proponents of locally sourced foods, such as Pollan and restaurateur Alice Waters (see Q\&A, below) - because "less transport and storage of fresh foods saves vitamins as well as energy". But Standage, poring over the numbers, believes that the current obsession with calculating 'food miles' is misguided. Transporting food may take less energy than growing or cooking it. So the carbon footprint of an English lamb chop, raised on energy-intensive maize feed, can be larger than that of a grass-fed one imported to Britain from New Zealand. If consumers want to save energy, he suggests, they should consider leaving the lid on the pan.
Arguments over food will continue as long as humans survive to eat it. As Standage contends, "every thing that every person has ever done ... has literally been fueled by food". That fact of history is unlikely to change.

Jascha Hoffman is a writer based in New York. e-mail: jascha@jaschahoffman.com

\title{
Q\&A: Education from the ground up
}

\begin{abstract}
When Alice Waters founded Chez Panisse restaurant in 1971, she used fresh ingredients from local suppliers and sparked a culinary revolution in Berkeley, California, that has spread worldwide. For the past decade she has been taking that revolution into education. Waters talks about teaching science in the garden, and the true cost of a school lunch.
\end{abstract}

\section{Why did you start teaching children to grow vegetables?}

A local school principal called me to see if engaging children in gardening and cooking could change the way they ate. Having worked in my restaurant for 25 years, I realized I shouldn't be alone in tapping such a pristine source of local food. At a jail in San Francisco, I had seen inmates so engaged in gardening that they did not want to leave. I knew there was something deep in the idea of putting your hands in the earth. That is what we discovered in my Edible Schoolyard programme: if kids grow it and cook it, they will want to eat it.

\section{How do you teach science through gardening?}

You can weave food into the curriculum in the most imaginative ways - the growing of it, the cooking of it, the eating of it. You can get young kids to count varieties of beans instead of buttons. When the kids go out in the garden, they measure the beds and calculate the number of seeds that have to be planted. They work on irrigation systems. They see how quickly the worms decompose the vegetables. It's science and they think it is fun. I was a teacher before I started my restaurant.

\section{What's wrong with most school lunches?}

In the United States, the schools get the least healthy foods, and there is not enough money to pay real cooks. You have a deadly combination of surplus commodities that are basically fast food and reimbursement that's so small that you cannot prepare fresh salads and fruits. The cost? An obesity epidemic, the pollution of the environment and the destruction of our culture.

\section{Should governments tell us how to eat?} We believe that eating is our own private turf. But if other people are eating poorly,

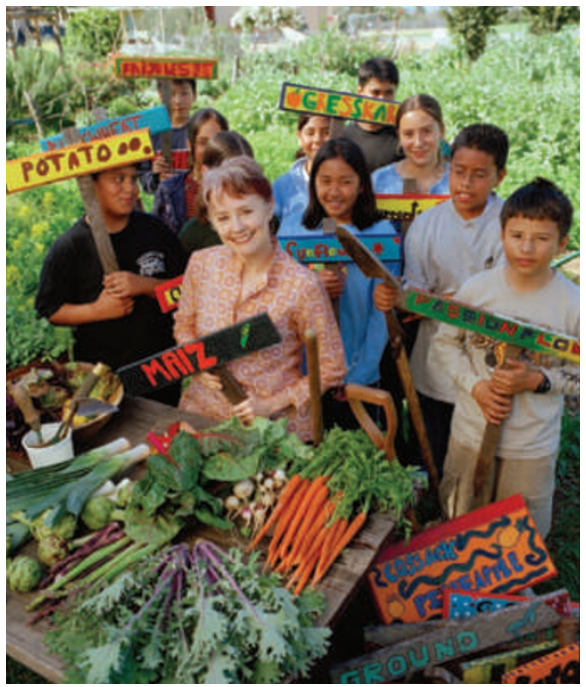

Alice Waters takes learning outdoors with her hybrid programme of gardening and science.

it raises the rates of everyone's health care. This is a global issue that governments must regulate. We have to decide what constitutes food. In France they have national health care, so they measure and weigh children to tell them how many calories they should have for lunch. We need 'edible education' to start at an early age. The government should pay up front for that, instead of cleaning up later with health care.

\section{Have you discussed this with the administration of Barack Obama?}

It has been my goal since 1992 to encourage every US president to plant a victory garden in the spirit of President Thomas Jefferson. I met Michelle Obama last summer, and I know people in Congress are talking about linking farms and schools. Hillary Clinton is a big proponent too. I call this a stimulus package. You nourish all children with food that is good, clean and fair. That means buying it from local sources. It is a moral issue. It cannot wait another day.

\section{What other food-education work is going} on outside of California?

We're concentrating now on New Orleans. Because it is so fertile and so in need after Hurricane Katrina we wanted to help, and in three years the programme has blossomed. It is expensive - it costs hundreds of thousands of dollars to hire the best teachers and to take care of visitors. The Yale University Sustainable Food Project of the past six years is also a success. It has integrated an organic farm that grows 250 varieties of fruits and vegetables into the curriculum. Hundreds of students volunteer to work in the gardens and they are demanding fair-trade coffee and grass-fed beef all over campus. I'm going to Harvard University soon to see whether we can change that old food system too.

\section{What about countries that are struggling to feed their children?}

I've been in touch with a teacher in Ghana who said, "For our ultimate survival, we have to engage the children in the cooking of their own food." Former United Nations secretary-general Kofi Annan has also talked about the green revolution in Africa. People in Africa haven't come to this from taste and beauty, as I did, but from the ideas of hunger and necessity. But we all arrive at the same place. We need to feed everybody on this planet.

Interview by Jascha Hoffman, a writer based in New York.

e-mail:jascha@jaschahoffman.com

Edible Schoolyard: A Universal Idea

Chronicle Books: 2008.80 pp. $\$ 24.95$ 